\title{
Resistencia De Salmonella Spp A Antibióticos Y Fluctuación Fisicoquímica Del Agua A Nivel Espacial En La Cuenca Media Del Río Usumacinta, México
}

\author{
María Concepción de la Cruz-Leyva, PhD \\ José Ulises González-de la Cruz, PhD \\ Vidaura Catalina Debelis Urbina, Ing \\ Hilda Guadalupe Alperte Rodríguez, Master
}

División Académica Multidisciplinaria de los Ríos, Universidad Juárez

Autónoma de Tabasco (UJAT), Tenosique, Tabasco, México

Carlos Alfonso Álvarez González, PhD

División Académica de Ciencias Biológicas, Universidad Juárez

Autónoma de Tabasco (UJAT), Tenosique, Tabasco, México

Carlos Alberto Cuenca-Soria, PhD

División Académica Multidisciplinaria de los Ríos, Universidad Juárez

Autónoma de Tabasco (UJAT), Tenosique, Tabasco, México

Doi:10.19044/esj.2020.v16n15p43～URL:http://dx.doi.org/10.19044/esj.2020.v16n15p43

\section{Resumen}

La presencia de antibióticos en cuerpos de agua es un indicador de su mal uso. Se realizaron muestreos en seis sitios con marcada influencia antropogénica en la cuenca media del río Usumacinta, México, durante la estación de seca, con la finalidad de estudiar la variación espacial fisicoquímica del agua y la resistencia antimicrobiana de Salmonella spp. La identificación bacteriana se realizó con pruebas bioquímicas convencionales. La resistencia bacteriana fue evaluada mediante la sensibilidad antibiótica a la amikacina (AK $30 \mu \mathrm{g}$ ), levofloxacina (LEV $5 \mu \mathrm{g}$ ), ceftriaxona (CRO $\mu \mathrm{g} 30$ ), cloranfenicol (CLO $30 \mu \mathrm{g}$ ), trímetropina-sulfametoxazol (TRI-SXT $25 \mu \mathrm{g}$ ), ampicilina (AM $10 \mu \mathrm{g}$ ), (cefalotina CF $30 \mu \mathrm{g}$ ), gentamicina (GE $10 \mu \mathrm{g}$ ), (netilmicina NET $30 \mu \mathrm{g}$ ), nitrofurantoína (NF $300 \mu \mathrm{g}$ ), cefepime (FEP $30 \mu \mathrm{g}$ ) y cefotaxima (CTX $30 \mu \mathrm{g}$ ); con la técnica de difusión estandarizada de Kirby Bauer. Los resultados detectaron 16 cepas correspondientes a Salmonella spp. Así mismo, los diámetros de los halos de inhibición del crecimiento bacteriano fueron significativos, por efecto del tipo de antibiótico empleado para las pruebas. Así como, por efecto del sitio de muestreo (p < 0.05). El 100\% de las cepas de Salmonella spp fueron sensibles a los antibióticos AK, LEV, CRO, GE, NET, FEP y la CTX; mientras el $93.7 \%$ fueron resistentes a la AM. 
Finalmente, la resistencia de Salmonella spp, a antibióticos puede verse afectada por el grado de perturbación antropogénica del sitio muestreado y según el tipo de antibiótico presente en el agua.

Palabras Clave: Río, Usumacinta, Resistencia, Salmonella, Antibióticos

\title{
Resistance Of Salmonella Spp to Antibiotics and Physicochemical Fluctuation Of Water at the Spatial Level in the Middle Basin of the Usumacinta River, Mexico
}

\author{
María Concepcion de la Cruz-Leyva, PhD \\ José Ulises Gonzalez-de la Cruz, PhD \\ Vidaura Catalina Debelis Urbina, Ing \\ Hilda Guadalupe Alperte Rodríguez, Master
}

División Académica Multidisciplinaria de los Ríos, Universidad Juárez Autónoma de Tabasco (UJAT), Tenosique, Tabasco, México

\section{Carlos Alfonso Alvarez Gonzalez, PhD}

División Académica de Ciencias Biológicas, Universidad Juárez

Autónoma de Tabasco (UJAT), Tenosique, Tabasco, México

Carlos Alberto Cuenca-Soria, PhD

División Académica Multidisciplinaria de los Ríos, Universidad Juárez

Autónoma de Tabasco (UJAT), Tenosique, Tabasco, México

\begin{abstract}
The presence of antibiotics in water bodies is an indicator of their misuse. Samples were conducted at six sites with marked anthropogenic influence in the middle basin of the Usumacinta River, Mexico, during the dry season. In order to study the physicochemical spatial variation of water and the antimicrobial resistance of Salmonella spp., bacterial identification was performed with conventional biochemical tests. Bacterial resistance was evaluated by the antibiotic sensitivity of amikacin (AK $30 \mu \mathrm{g}$ ), levofloxacin (LEV $5 \mu \mathrm{g}$ ), ceftriaxone (CRO $\mu \mathrm{g}$ 30), chloramphenicol (CLO $30 \mu \mathrm{g}$ ), trimetropin-sulfamethoxazole (TRI-SXT $25 \mu \mathrm{g}$ ), ampicillin (AM $10 \mu \mathrm{g}$ ), cephalothin (CF $30 \mu \mathrm{g}$ ), gentamicin (GE $10 \mu \mathrm{g}$ ), netilmicin (NET $30 \mu \mathrm{g}$ ), nitrofurantoin (NF $300 \mu \mathrm{g}$ ), cefepime (FEP $30 \mu \mathrm{g}$ ) and cefotaxime (CTX 30 $\mu \mathrm{g}$ ); with the standardized diffusion technique of Kirby Bauer. The results
\end{abstract}


showed the diameters of the bacterial growth inhibition halos were significant, due to the type of antibiotic used for the tests. In addition, the effect of the sampling site was significant ( $\mathrm{p}<0.05) .100 \%$ of Salmonella spp strains were sensitive to antibiotics AK, LEV, CRO, GE, NET, FEP and CTX; while 93.7 $\%$ were resistant to AM. Finally, the resistance of Salmonella spp to antibiotics can be affected by the degree of anthropogenic disturbance of the sampled site, and according to the type of antibiotic present in the water.

Keywords: Usumacinta River, Antibiotic, Salmonella, Resistance

\section{Introducción}

La calidad del agua puede verse afectada por la presencia de contaminantes químicos que afectan sus características físicas: turbiedad, color, olor y sabor, temperatura, $\mathrm{pH}$; al igual que sus características químicas: oxígeno disuelto, alcalinidad (bicarbonatos, carbonatos, hidróxido, sulfuro, bisulfuro, silicato y fosfato), cloruros, dureza equivalente a carbonato de calcio (calcio y magnesio), nitritos (sales de ácido nitroso, $\mathrm{HNO}_{2}$ ) y nitratos (sales del ácido nítrico, $\mathrm{HNO}_{3}$ ). El río Usumacinta, es uno de los más importantes de México y Meso-América no solo por su extensión, sino por el importante caudal que representa anualmente. Este río se forma en las partes altas de la sierra de los Cuchumatanes, específicamente en el Departamento de Totonicapan en Guatemala y desemboca en el Golfo de México (NOM037-PESC-2004). La caracterización fisicoquímica del agua de ríos ofrece nuevos conocimientos que pueden coadyuvar a comprender este hábitat, donde existen organismos pesqueros y microdiversidad que dependen entre otros de los nutrientes presentes en estos ecosistemas acuáticos.

Un problema que puede afectar la calidad del agua en embalses de agua naturales, es la descarga de grandes volúmenes de aguas residuales no tratadas, que pueden disminuir la capacidad de dilución y autodepuración (Gil et al., 2012). En la región del río Usumacinta, las fuentes comunes de contaminación abarcan las actividades agrícolas, las descargas domésticas e industriales sin tratamiento; lo cual afecta a la salud humana y la dinámica natural del ecosistema, lo que deriva en la presencia de organismos altamente patógenos para la salud silvestre y humana en los ambientes acuáticos (Durán-Mendoza et al., 2018). Así mismo, el agua es uno de los más importantes hábitats y rutas, para la dispersión de la resistencia bacteriana a antibióticos en los ecosistemas acuáticos (Ferro et al., 2017).

A este respecto en México, cada año se reportan alrededor de 110,000 casos de salmonelosis, asociados al consumo de agua y alimentos contaminados (Dirección General de Epidemiología, 2006), y pocas veces se identifica el origen de las bacterias. La automedicación, principalmente de ciprofloxacino y aminoglucósidos es una práctica común, que no establece un 
buen tratamiento de dosis-tiempo (Bada-Alambedji et al., 2006); lo cual puede provocar niveles significativos de resistencia a los antimicrobianos, con un incremento en emergencias de Salmonella y Escherichia coli (Duffy et al., 2005; Musgrove et al., 2006). Es importante citar que las descargas de aguas residuales a afluentes naturales, es un punto de discusión que incluye no sólo la salida de bacterias con características patógenas, sino que también plantea un riesgo como fuente de vectores de transmisión de resistencia a antibióticos (Martínez y Villalobos, 2008). Más aún, genes asociados a la resistencia bacteriana a antibióticos, han sido encontrados en sedimentos de aguas estuarinas; genes que comúnmente se encuentran presentes en humanos y animales domésticos ((Zhu et al., 2017).

La mayoría de los compuestos químicos como los antibióticos utilizados en las diferentes prácticas médicas, son eliminados directamente a los efluentes hospitalarios y redes municipales sin metabolizar o parcialmente metabolizados, impactando finalmente en las aguas subterráneas, los ambientes acuáticos y en los sedimentos (Watkinson et al., 2007). Estos antimicrobianos, permanecen en el ambiente ejerciendo una presión selectiva durante prolongados períodos, provocando un incremento de resistencia en los patógenos de los peces y en la alteración de la flora bacteriana de los sedimentos y del ambiente acuático (Harakeh et al., 2006).

El río Usumacinta en su paso hacia el Golfo de México fluye entre otros lugares por Tenosique, Tabasco, México, donde recibe descargas residuales de aguas de diferentes naturalezas como industriales y municipales, las cuales, presentan contaminación fisicoquímica y microbiológica, ocasionando un deterioro, gradual y sostenido como ha sucedido en otros ríos mexicanos (Durán-Mendoza et al., 2018). Los ríos urbanos son ecosistemas impactados que pueden jugar un papel importante, como reservorios de bacterias resistentes a diversos antibióticos (Proia et al., 2018). Así que, resulta prioritario estudiar la sensibilidad antimicrobiana en enterobacterias aisladas del agua del río Usumacinta, Tabasco, México afín de generar información sobre el entendimiento de la resistencia a antibióticos en ambientes acuáticos y que coadyuve a la salud de las personas expuestas (Watkinson et al., 2007). Por lo que el objeto de la presente investigación fue estudiar la variación espacial, de la caracterización fisicoquímica del agua; así como la resistencia a la actividad antimicrobiana de la AK, LEV, CRO, CLO, TRI-SXT, AM, CF, GE, NET, NF, FEP y la CTX; de 16 cepas bacterianas del género Salmonella.

\section{Material y Métodos}

\section{Obtención de muestras y determinación de parámetros fisicoquímicos}

Los sitios de muestreo se muestran en la Figura 1. Los sitios fueron seleccionados de acuerdo al mayor impacto antropogénico (Durán-Mendoza et al., 2018), caracterizadas por áreas de descarga de aguas residuales, áreas 
de afluencia de lanchas de pescadores y para transporte de personas hacia sus comunidades. Las muestras fueron colectadas (con dos repeticiones en cada sitio); durante la temporada de seca (abril a mayo de 2015). La recolección de las muestras se realizó de 7:45 a 11:45 am, tomando muestras en frascos de vidrio estéril y llevadas al laboratorio a $10^{\circ} \mathrm{C}$. Los registros de la temperatura y el $\mathrm{pH}$ fueron tomados in situ. Se tomaron muestras de agua, de los sitios seleccionados para el análisis, en ppm $(\mathrm{mg} / \mathrm{mL})$, de la alcalinidad $\left(\mathrm{CaCO}_{3}\right)$, dióxido de carbono $\left(\mathrm{CO}_{2}\right)$, dureza $\left(\mathrm{CaCO}_{3}\right)$ y oxígeno disuelto (OD), en el laboratorio, siguiendo las recomendaciones del fabricante (kit La Mote ${ }^{\circledR}$ ).

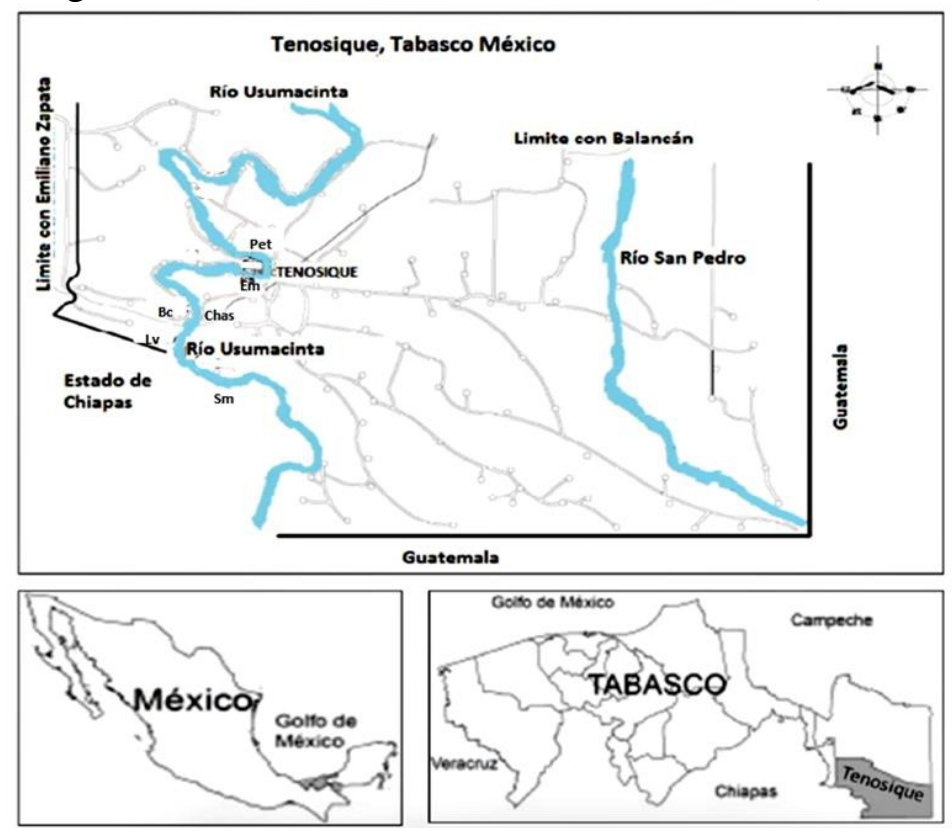

Figura 1. Ubicación de los sitios de muestreo en la cuenca del río Usumacinta, Tabasco, México: Sm (Santa Margarita), Lv (Lindavista), Bc (Boca del Cerro), Chas (Chaschin), Em (Embarcadero), Pet (Petunia). Fuente: Duran-Mendoza et al., 2018.

\section{Toma de muestras para aislamiento, identificación y resistencia bacteriana}

Para las pruebas de asilamiento e identificación bacteriana, se recolectaron 56 muestras de agua por duplicado en la cuenca media del río Usumacinta en Tenosique, Tabasco, en la temporada de secas durante los meses de abril-mayo del 2013. Las muestras se recolectaron en envases de vidrio estéril de $500 \mathrm{~mL}$ a $2 \mathrm{~m}$ de la orilla y a una profundidad de $30 \mathrm{~cm}$ basándonos en la metodología de Castañeda et al., (2009). Las muestras fueron transportadas al laboratorio a una temperatura de $10^{\circ} \mathrm{C}$, donde se almacenaron a $-4^{\circ} \mathrm{C}$ hasta su uso, no excediendo un periodo de $4 \mathrm{~h}$ (NMX-AA-42-1987). En lo que respecta a las pruebas bacterianas, los análisis fueron llevados a cabo de acuerdo con la norma oficial mexicana NOM-114-SSA1-1994. Las 
colonias morfológicamente sospechosas a Salmonella spp, fueron sembradas en medio de alta selectividad: agar CHROmagar Salmonella BD ${ }^{\circledR}$ de este agar se extrajeron colonias para pruebas bioquímicas en Agar Hierro Triple Azúcar (TSI) y Agar Lisina Hierro (LIA). Además, se inocularon tubos con medio Sulfhídrico Indol Movilidad (SIM), para la identificación de indol, ácido sulfhídrico y movilidad (Ugollini, 2006). Se realizó tinción de Gram (MacFaddin, 2003), la prueba de la catalasa (Ugollini, 2006), y las pruebas bioquímicas convencionales para género y especie (ácido sulfídrico, indol, citrato, agar hierro triple azúcar, descarboxilasa lisina, rojo de metilo y catalasa (Cervantes et al., 2006). Para la realización de la prueba de susceptibilidad de bacterias Salmonella spp. a antibióticos, se empleó el método de difusión en agar descrito por Bauer et al., (1966), según los lineamientos establecidos por el Instituto para Estándares Clínicos y de Laboratorio (CLSI, 2011; NCCLS, 2004).

\section{Pruebas de difusión estandarizada de Kirby-Bauer}

Para las pruebas de difusión estandarizada de Kirby-Bauer se analizaron 15 cepas confirmativas a Salmonella ssp aisladas previamente en condiciones estériles (NOM-114-SSA1-1994). Misma que fueron preenriquecidas por $24 \mathrm{~h}$ y resembrados en agar MacConkey por otras $24 \mathrm{~h}$ a 37 ${ }^{\circ} \mathrm{C}$. Las colonias puras fueron sembradas en caldo nutritivo incubado a $37{ }^{\circ} \mathrm{C}$, hasta alcanzar la turbidez estándar de $0.5 \mathrm{MacFarland}$. Una vez sembrada la bacteria en agar Mueller-Hinton ${ }^{\circledR}$, se colocó un sensidisco que contenía 12 antibióticos (BIO-RAD ®) específicos para bacterias gram negativas II (Catálogo: 71080580): amikacina (AK) $(30 \mu \mathrm{g})$, levofloxacina (LEV) $(5 \mu \mathrm{g})$, ceftriaxona (CRO) (30 $\mu \mathrm{g})$, cloranfenicol (CLO) $(30 \mu \mathrm{g})$, trimetoprimsulfametoxazol (TRI-SXT) $(25 \mu \mathrm{g})$, ampicilina (AM) $(10 \mu \mathrm{g})$, cefalotina (CF) (30 $\mu \mathrm{g})$, gentamicina (GE) $(10 \mu \mathrm{g})$, netilmicina (NET) (30 $\mu \mathrm{g})$, nitrofurantolina (NF) $(300 \mu \mathrm{g})$, cefepime (FEP) $(30 \mu \mathrm{g})$ y cefotaxima (CTX) $(30 \mu \mathrm{g})$, la prueba se repitió por triplicado. Las placas sembradas con los sensidiscos fueron incubadas a $37^{\circ} \mathrm{C}$, durante $24 \mathrm{~h}$. Los diámetros de los halos de inhibición de crecimiento bacteriano, fueron medidos con un vernier electrónico y fueron interpretados según tablas estándares. Los halos de inhibición fueron clasificados en sensibles (S), intermedios (I) y resistentes (R), de acuerdo con las categorías e interpretación establecidas por la CLSI (2011).

\section{Análisis estadístico}

Para los datos de parámetros físicoquímicos que no cumplieron los supuestos de normalidad $\mathrm{y}$ homocedasticidad, fueron sometidos a la transformación de la forma $X^{\prime}=[$ raíz cuadrada $(X+1)+0.375] /[$ raíz cuadrada $(\mathrm{X})+15]$, donde, $\mathrm{X}^{\prime}$ es el valor $\mathrm{GH}$-ésimo transformado y $\mathrm{X}$ es el 
valor GH-ésimo en crudo (Cuenca et al., 2013a). Para el análisis de datos de resistencia bacteriana a distintos antibióticos, se empleó una prueba no paramétrica de Friedman, para determinar posibles diferencias significativas en los halos de inhibición promedio, por efecto tanto del tipo de antibiótico, como del sitio de muestreo. Así mismo, se emplearon las pruebas de correlación de Pearson/Spearman, de acuerdo a la normalidad de los datos. Para todas las pruebas, se empleó un nivel de significancia de 0.05. Para el cómputo de los datos, se utilizó el programa Statistica $^{\mathrm{TM}}$ v8.

\section{Resultados}

\section{Fluctuación espacial de variables ambientales}

En la Tabla 1 se presentan los valores promedio de parámetros físicos y químicos, obtenidos en agua de la cuenca media del río Usumacinta, México. El potencial de hidrógeno $(\mathrm{pH})$ fue de $7.1 \pm 0.1$ (Santa Margarita) a $7.9 \pm 0.2$ (Embarcadero). Con lo que respecta a la temperatura, se registraron valores entre $28.3 \pm 0.1$ (Lindavista) y $30.2 \pm 0.6^{\circ} \mathrm{C}$ (Chaschin). La alcalinidad por su parte, mostró valores entre $128.0 \pm 5.7$ (Lindavista) y $135.0 \pm 27.0$ ppm (Boca del Cerro). En tanto que el dióxido de carbono, que tuvo valores entre $19.1 \pm$ 5.5 (Embarcadero) y $27.7 \pm 8.4$ ppm (Chaschin). Mientras tanto, la dureza por sales de carbonato de calcio que fluctuó entre 250.0 2.8 (Lindavista) y 352 \pm 8.5 ppm (Petunia). Por otro lado, el oxígeno disuelto, varió entre $6.1 \pm 2.3$ (Chaschin) y $7.8 \pm 0.3$ ppm (Petunia).

Tabla 1. Fluctuación fisicoquímica del agua de la cuenca media del río Usumacinta, México, por sitios de muestreo.

\begin{tabular}{cccccccc}
\hline No. & Sitio & $\mathrm{T}^{\circ} \mathrm{C}$ & $\mathrm{pH}$ & Alcalinidad & $\mathrm{CO}_{2}$ & Dureza & $\mathrm{OD}$ \\
\hline 1 & $\mathrm{Bc}$ & $29.3 \pm 0.4$ & $7.8 \pm 0.1$ & $135.0 \pm 27.0$ & $19.4 \pm 7.7$ & $328.0 \pm 46.0$ & $7.6 \pm 1.3$ \\
4 & Chas & $30.2 \pm 0.6$ & $7.6 \pm 0.4$ & $129.0 \pm 8.0$ & $27.7 \pm 8.4$ & $336.7 \pm 43.1$ & $6.1 \pm 2.3$ \\
5 & Em & $30.1 \pm 0.3$ & $7.9 \pm 0.2$ & $133.0 \pm 31.0$ & $19.2 \pm 6.5$ & $337.3 \pm 21.9$ & $7.5 \pm 0.7$ \\
6 & Pet & $30.0 \pm 0.8$ & $7.4 \pm 0.3$ & $130.0 \pm 12.0$ & $19.1 \pm 5.5$ & $352.0 \pm 8.5$ & $7.8 \pm 0.3$ \\
8 & Sm & $28.7 \pm 0.2$ & $7.7 \pm 0.1$ & $132.0 \pm 11.3$ & $25.8 \pm 0.4$ & $284.9 \pm 33.9$ & $7.5 \pm 0.1$ \\
9 & Lv & $28.3 \pm 0.1$ & $7.7 \pm 0.2$ & $128.0 \pm 5.7$ & $27.3 \pm 0.4$ & $250.0 \pm 2.8$ & $7.2 \pm 0.2$ \\
\hline
\end{tabular}

Sm (Santa Margarita), Lv (Lindavista), Bc (Boca del Cerro), Chas (Chaschin), Em (Embarcadero), Pet (Petunia), OD (Oxígeno disuelto).

\section{Resistencia antimicrobiana de Salmonella spp}

A partir de 56 muestras de agua recolectadas, en los seis sitios con impacto antropogénico en la cuenca del río Usumacinta, se identificaron 15 cepas de Salmonella spp: bacilos Gram negativos, anaerobios facultativos, movilidad, catalasa positivos, oxidasa negativos, producción de gas y ácido a partir de la glucosa, indol negativo, producción de ácido sulfhídrico, citrato de Simmons positivo, descarboxilación de lisina y ornitina. 
En la Tabla 2 se presenta el patrón de resistencia de 12 antimicrobianos evaluados en las 15 cepas de Salmonella spp, aisladas de los sitios de muestreo del río Usumacinta.

Tabla 2. Sensibilidad de 15 cepas de Salmonella spp, aisladas del agua de la cuenca media del río Usumacinta, en temporada seca. Valores expresados en porciento.

\begin{tabular}{ccccccccccccc}
\hline & AK & AM & LEV & CF & CRO & CLO & GE & NET & NF & FEP & TSXT & CTX \\
\hline $\mathrm{R}$ & 0 & 93.7 & 0 & 68.7 & 0 & 0 & 0 & 0 & 12.5 & 0 & 12.5 & 0 \\
$\mathrm{~S}$ & 100 & 6.3 & 100 & 25 & 100 & 87.5 & 100 & 100 & 75 & 100 & 87.5 & 100 \\
$\mathrm{I}$ & 0 & 0 & 0 & 6.3 & 0 & 12.5 & 0 & 0 & 12.5 & 0 & 0 & 0 \\
\hline
\end{tabular}

AK (Amikacina), AM (Ampicilina), LEV (Levofloxacina), CF (Cefalotina), CRO (Ceftriaxona), CLO (Cloranfenicol), GE (Gentamicina), NET (Netilmicina), NF (Nitrofurantoína), FEP (Cefepime), TSXT (Trimetropin-Sulfametoxazol), CTX (Cefotaxima), R (resistente), S (sensible), I (intermedio).

Por otro lado, los distintos valores de los halos de inhibición bacteriana, según el sitio de muestreo, se pueden visualizar en la Tabla 3. Los resultados de los análisis para las cepas de Salmonella spp, mostraron que el $100 \%$ de ellas fueron sensibles a la AK $(30 \mu \mathrm{g})$, LEV $(5 \mu \mathrm{g}), \mathrm{CRO}(30 \mu \mathrm{g})$, GE $(10 \mu \mathrm{g})$, NET $(30 \mu \mathrm{g})$, FEP $(30 \mu \mathrm{g})$ y la CTX $(30 \mu \mathrm{g})$. De manera paralela, las pruebas revelaron que el $93.7 \%$ de las cepas aisladas de Salmonella spp., fueron resistentes a la AM, seguido de un $68.7 \%$ de resistencia a la CF (30 $\mu \mathrm{g})$.

\section{Correlación de la resistencia bacteriana a antibióticos con el pH}

Los diámetros de los halos de inhibición bacteriana y el pH en el agua, observaron correlación positiva para la LEV $5 \mu \mathrm{g}(\mathrm{r}=0.73, \mathrm{p}<0.05)$, y correlación positiva moderada para la AK $30 \mu \mathrm{g}$, TRI-SXT $25 \mu \mathrm{g}$, CRO 30 $\mu \mathrm{g}$, NF $30 \mu \mathrm{g}$ y FEP $30 \mu \mathrm{g}\left(\mathrm{r}_{1}=0.3000, \mathrm{r}_{2}=0.3483, \mathrm{r}_{3}=0.3882, \mathrm{r}_{4}=0.5404\right.$ y $\left.\mathrm{r}_{5}=0.5555 ; \mathrm{p}<0.05\right)$, de manera respectiva.

Tabla 3. Diámetros de los halos de inhibición promedio $(\mathrm{mm})$ de Salmonella spp, por efecto del tipo de antibiótico y sitio de muestreo.

\begin{tabular}{|c|c|c|c|c|c|c|}
\hline \multirow{2}{*}{ 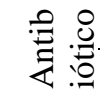 } & \multicolumn{6}{|c|}{ Sitios de muestreo } \\
\hline & $\mathrm{Sm}$ & Lv & $\mathrm{Bc}$ & Chas & $\mathrm{Em}$ & Pet \\
\hline $\mathrm{AK}$ & $19.8 \pm 4.3$ & $14.5 \pm 6.6$ & $24.0 \pm 2.6$ & $20.5 \pm 3.9$ & $21.2 \pm 4.5$ & $25.9 \pm 2.6$ \\
\hline $\mathrm{AM}$ & $0.0 \pm 0.0$ & $7.5 \pm 9.9$ & $0.0 \pm 0.0$ & $0.0 \pm 0.0$ & $0.0 \pm 0.0$ & $0.0 \pm 0.0$ \\
\hline LEV & $22.7 \pm 3.2$ & $25.0 \pm 7.3$ & $26.4 \pm 3.9$ & $24.8 \pm 4.4$ & $22.8 \pm 2.8$ & $31.2 \pm 3.2$ \\
\hline $\mathrm{CF}$ & $0.0 \pm 0.0$ & $18.9 \pm 4.8$ & $0.0 \pm 0.0$ & $1.8 \pm 0.2$ & $0.0 \pm 0.0$ & $22.5 \pm 4.4$ \\
\hline $\mathrm{CRO}$ & $14.1 \pm 3.7$ & $22.5 \pm 6.1$ & $20.6 \pm 3.9$ & $19.4 \pm 2.0$ & $16.9 \pm 3.5$ & $24.6 \pm 3.4$ \\
\hline CLO & $23.7 \pm 4.4$ & $25.9 \pm 1.2$ & $25.3 \pm 4.2$ & $19.7 \pm 8.8$ & $26.0 \pm 2.7$ & $28.9 \pm 5.2$ \\
\hline GE & $17.6 \pm 3.3$ & $20.1 \pm 4.3$ & $19.5 \pm 1.6$ & $18.6 \pm 5.0$ & $19.7 \pm 5.1$ & $22.4 \pm 3.6$ \\
\hline NET & $23.0 \pm 5.1$ & $23.3 \pm 2.7$ & $23.8 \pm 4.0$ & $20.7 \pm 5.9$ & $23.0 \pm 4.7$ & $24.8 \pm 2.5$ \\
\hline
\end{tabular}




$$
\begin{array}{ccccccc}
\text { NF } & 15.5 \pm 4.6 & 16.0 \pm 4.4 & 17.1 \pm 3.3 & 11.3 \pm 2.9 & 12.9 \pm 3.3 & 22.1 \pm 3.4 \\
\text { FEP } & 20.9 \pm 4.3 & 23.2 \pm 4.0 & 26.0 \pm 3.4 & 23.9 \pm 2.2 & 23.0 \pm 2.3 & 29.1 \pm 4.2 \\
\text { TSX } & 22.2 \pm 3.9 & 25.4 \pm 2.7 & 25.9 \pm 4.1 & 22-6 \pm 6.4 & 22.3 \pm 2.1 & 30.9 \pm 3.6 \\
\text { CTX } & 25.3 \pm 3.1 & 26.8 \pm 5.6 & 24.4 \pm 3.6 & 25.2 \pm 3.1 & 20.7 \pm 4.1 & 32.2 \pm 5.5
\end{array}
$$

AK (Amikacina), AM (Ampicilina), LEV (Levofloxacina), CF (Cefalotina), CRO (Ceftriaxona), CLO (Cloranfenicol), GE (Gentamicina), NET (Netilmicina), NF (Nitrofurantoína), FEP (Cefepime), TSXT (Trimetropin-Sulfametoxazol), CTX (Cefotaxima), Sm (Santa Margarita), Lv (Lindavista), Bc (Boca del Cerro), Chas (Chaschin), Em (Embarcadero), Pet (Petunia).

\section{Discusión}

Los antibióticos de elección para la salmonelosis son generalmente las cefalosporinas y quinolonas (Junco et al., 2006). En el presente estudio Salmonella spp, evidenció una alta sensibilidad antimicrobiana del 100\% para amikacina, levofloxacina, gentamicina, netilmicina, nitrofurantoína, cefepime y ceftriaxona; mientras que mostró una resistencia cercana al $100 \%$ a la ampicilina y cercana al $70 \%$ a la cefalotina, lo que pudiera ser un claro indicador del abuso de éstas dos últimas, con los daños colaterales al ecosistema acuático, que ello implican. Una vez presentes en agua, los antibióticos pueden afectar no solo la salud humana, sino también la función del ecosistema en su totalidad, debido a su alta toxicidad para con las bacterias que representan las bases de las cadenas tróficas y ciclos de nutrimentos en el agua (González-Pleiter et al., 2019). En otro sentido, los ambientes dulceacuícolas son altamente susceptibles a posible contaminación, debido a residuos de antibióticos liberados a partir de fuentes agrícolas, descargas residuales, y procesos de lixiviación de suelos contaminados urbanos, lo que hace los cuerpos de agua dulce, reservorios de antibióticos (Nnadozie \& Odume, 2019). Así, aunque los antibióticos que resultaron más efectivos en la inhibición del crecimiento bacteriano no mostraron susceptibilidad de Salmonella spp, el mal manejo de antibióticos para fines ganaderos y avícolas y en la región del Usumacinta, México, pudiera repercutir en resistencia gradual en el tiempo (Duran-Mendoza et al., 2018). El uso indiscriminado y sobre uso de antibióticos, puede conducir a la prevalencia de resistencia bacteriana a antibióticos (Levy y Marshall, 2004).

En este sentido y de acuerdo con los resultados obtenidos, cabe mencionar que Chaschin, Embarcadero y Santa Margarita, mostraron la mayor resistencia bacteriana a antibióticos de los sitios estudiados, lo cual puede ser debido a la presencia de grandes centros poblacionales, como la ciudad de Tenosique (donde se ubica el Embarcadero y Chaschin). Luego entonces, la actividad antropogénica puede estar asociada a la presencia de antibióticos en el río Usumacinta, México. Con relación a esto último, Zhu et al., (2017), 
hallaron una fuerte correlación entre la presencia de genes asociados a la resistencia a antibióticos, con la actividad humana en sedimentos estuarinos, a lo largo de $400 \mathrm{~km}$ de la zona costera china. Cabe recalcar adicionalmente que gran parte de la actividad económica en zonas aledañas rurales al río Usumacinta, es sostenida por la actividad ganadera, en la que tiene lugar el uso continuo de antibióticos para fines veterinarios (Duran-Mendoza et al., 2018). Por consiguiente, es menester continuar con las investigaciones que permitan dilucidar también, los posibles daños de los antibióticos a la flora y fauna del río Usumacinta, México, ya que de acuerdo con Marti et al., (2018), fue posible evidenciar la presencia de genes relacionados a la resistencia a antibióticos, en el mucus intestinal de trucha café y carpa común, en la región catalana de España.

Con lo que respecta a la correlación positiva observada entre los valores de $\mathrm{pH}$ y los halos de inhibición de cepas bacterianas de Salmonella $\mathrm{sp}$ aisladas, se encontró que a pesar de las mínimas variaciones de $\mathrm{pH}$ registradas en el agua, éstas posiblemente pudieran incidir, en los mecanismos de resistencia de Salmonella a estos antibióticos. A reserva de que es necesario llevar a cabo muchos más estudios para confirmar lo anterior, esta posible relación ( $\mathrm{pH}$-resistencia bacteriana) pudiera ser considerada, como un indicador de perturbaciones en los ecosistemas acuáticos, tal como lo sugiere el trabajo de Orr et al., (2005), con respecto a la acidificación de los océanos del hemisferio sur, por la actividad humana.

Es menester puntualizar así mismo que, la presencia de los genes asociados a la resistencia a antibióticos y otros elementos contaminantes en los sedimentos, ofrece la oportunidad de reconstruir el historial de contaminación en los cuerpos de agua, como sugieren Devarajan et al., (2015), en su trabajo de acumulación de éstos genes de resistencia a antibióticos, carga bacteriana y metales, en lagos de Europa Central. No obstante, es necesario dilucidar la posible relación entre el pH y la resistencia a antibióticos en cuerpos de agua dulce; a nivel de cepas bacterianas del género Salmonella y otros grupos bacterianos más, como posibles indicadores de perturbación de los ambientes acuáticos también en regiones urbanas, como sugieren Proia et al., (2018) en su estudio de la resistencia a antibióticos en ríos urbanos, como cuerpos receptores de aguas municipales tratadas. Es necesario considerar también que en la presente investigación, solo se colectaron muestras durante la época de secas para las pruebas de resistencia bacteriana. Por lo que habría que evaluar así mismo, es la consistencia o inconsistencia de esta posible relación, con la estacionalidad misma.

\section{Conclusión}

La presente investigación incentiva a llevar a cabo más estudios relacionados con la influencia de otros factores como la estacionalidad, en la 
fluctuación de los parámetros físicos y químicos en el agua del río Usumacinta. Es necesario también realizar más investigaciones centradas en la posible relación de parámetros fisicoquímicos como el $\mathrm{pH}$, con la resistencia bacteriana a antibióticos; con las posibles implicaciones en el ecosistema acuático y la salud humana que ello derivan. Es menester estudiar la posible presencia de antibióticos no solo en agua, sino también en sedimentos y biota de la cuenca del río Usumacinta, Tabasco, México. Así mismo, cabe dilucidar los genes implicados en la resistencia a antibióticos de Salmonella spp. y de otros grupos bacterianos de alto impacto en la salud humana. Finalmente, es menester cobrar conciencia del no abuso y/o mal manejo de antibióticos en la actividad humana, por sus repercusiones negativas en el ecosistema acuático.

\section{Agradecimientos}

A Hernández-Gómez R., por su contribución a la elaboración del mapa donde se ubicaron los sitios de muestreos en la cuenca del río Usumacinta, Tabasco, México (Figura 1).

\section{References:}

1. Bada-Alambedji, R., Fofana, A., Seydi, M., \& Akakpom, A. J. (2006). Antimicrobial Resistance of Salmonella Isolated from Poultry Carcasses in Dakar (Senegal). Brazil. J. Microbiol., 37: 510-515.

2. Bauer A., Kirby W., Sherris I., \& Turck, M. (1966). Antibiotic susceptibility testing a standardized single disk method. Amer. J. Clin. Pathol., 45: 493-496.

3. Castañeda, R., Guaimacuto, L. P., \& Figueroa R. Y., \& Fuentes, L. (2009). Susceptibilidad a antibióticos de bacterias indicadoras de contaminación fecal aisladas de aguas y sedimentos marinos de playas de la isla de Margarita, Venezuela. Saber, Universidad de Oriente, Venezuela, 21(1): 12-19.

4. Cervantes, C., Espino-Saldaña, A. E., Aguilar F. A., León Rodríguez I. L., \& Rivera M. E. (2006). Interacciones microbianas con metales pesados. Revista Latinoamericana de Microbiología, 48(2): 203-210.

5. CLSI, The Clinical and Laboratory Standards Institute. (2011). Performance standards for antimicrobial susceptibility testing. NCCLS, Wayne, USA.

6. Cuenca, C. A., Álvarez-González, C. A., Ortiz-Galindo, J. L., Guerrero-Zárate, R., Perera-García, M. A., Hernández-Gómez, R. E., \& Nolasco-Soria, H. (2013a). Digestibilidad in vitro de ingredientes proteínicos en la mojarra castarrica Cichlasoma urophthalmus. Ecosistemas y Recursos Agropecuarios, 29(3): 263-275.

7. Devarajan N., Laffite A., Graham N. D., Meijer M., Prabakar K., Mubedi J. I., Elongo V., Mpiana P. T., Ibelings B. W., Wildi W., \& 
Poté J. (2015). Accumulation of Clinically Relevant AntibioticResistance Genes, Bacterial Load, and Metals in Freshwater Lake Sediments in Central Europe. Environmental Science Technology, 49(11): 6528-6537.

8. DGE (Dirección General de Epidemiología). (2006). Información Epidemiológica de Morbilidad. México. http://www.dgepi.salud.gob.mx consultado el 23 de febrero de 2013.

9. Duffy E. A., Lucia, L. M., Kells, J. M., Castillo, A., Pillai, S. D., \& Acuff, G. R. (2005). Concentration of Escherichia coli and genetic diversity and antibiotic resistance profiling of Salmonella isolated from irrigation water, packing shed equipment, and fresh produce in Texas. J. Food Prot., 68: 70-79.

10. Durán-Mendoza, T, González-de la Cruz, J.U, González-Pérez, M., Pérez-Sánchez, C. C., Hernández-Gómez, R., Cuenca-Soria, C. A., \& de la Cruz-Leyva, M.C. (2018). Calidad Microbiológica del Agua en la Cuenca Media del río Usumacinta, Tabasco, México. European Scientific Journal, 14 (19): 46-59.

11. Ferro G., Guarino F., Cicatelli A., \& Rizzo L. (2017). B-lactams resistance gene quantification in an antibiotic resistant Escherichia coli water suspension treated by oxidation with $\mathrm{UV} / \mathrm{H} 2 \mathrm{O} 2$. Journal of Hazardous Materials, 323(A): 426-433.

12. Gil, M. J., Soto, A. M., Usma, J. I., Gutiérrez, O. D. (2012). Contaminantes emergentes en aguas, efectos y posibles tratamientos. Producción + Limpia, 7(2): 52-73.

13. González-Pleiter, M., Cirés, S., Hurtado-Gallego, J., Leganés, F., Fernández-Piñas, F., \& Velásquez, D. (2019). Ecotoxicological assessment of antibiotics in freshwater using Cyanobacteria. En Cyanobacteria (págs. 399-417). Madrid: España.

14. Harakeh, S., Yassine, H., \& El-Fadel, M. 2006. Antimicrobialresistant patterns of Escherichia coli and Salmonella strains in the aquatic Lebanese environments. Environmental Pollution, 143(2): 269-277.

15. Hisham, Z., \& Finch, R. (2000). Resistencia antibiótica en el año 2000. Enferm. Infecc. Microbiol. Clin., 19: 91-92.

16. Junco, R., Suarez, M., Weng, Z., Chiroles, S., González, M., Díaz, O., \& Rodríguez, M. (2006). Sensibilidad antimicrobiana en bacterias de origen ambiental. Hig. Sanid. Ambient., 6: 150-159.

17. Levy, S. B. \& Marshall, B. (2004). Antibacterial resistance worldwide: causes, challenges and responses. Nat. Med., 10,S122-S129. https://doi.org/10.1038/nm1145.

18. MacFaddin, J. (2003). Pruebas bioquímicas para la identificación de bacterias de importancia clínica. Montevideo: Médica Panamericana. 
19. Marti E., Huerta B., Rodríguez-Mozaz S., Barceló D., Marcé R., \& Balcázar J. L. (2018). Abundance of antibiotic resistance genes and bacterial community composition in wild freshwater fish species. Chemosfere, 196: 115-119.

20. Martínez, R .E., \& Villalobos, L.B. 2008. Susceptibilidad antimicrobiana de cepas de Escherichia coli aisladas de alimentos y aguas residuales en Cumaná, Venezuela. Saber, Universidad de Oriente, Venezuela., 20(2): 172-176.

21. Musgrove, M. D., Jones, J., Northcutt, N., Cox, M., Harrison, P., Ferdorka, \& Ladely, S. (2006). Antimicrobial resistance in Salmonella and Escherichia coli isolated from commercial shell eggs. Poultry Sci. Assoc., 85: 1665-1669.

22. NCCLS (National Committe for Clinical Laboratory Standars), (2004). Performance standards for antimicrobial disk susceptibility test- ten Informational supplement: approved standard M100-S10 (M2). Wayne, P.A.

23. NMX-AA-42. (1987). Bienes y servicios. Determinación de bacterias coliformes totales, coliformes fecales (termotolerantes) y Escherichia coli. Técnica del número más Probable (NMP).

24. Nnadozie, C. F., \& Odume, O. N. (2019). Freshwater environments as reservoirs of antibiotic resistant bacteria and their role in the dissemination of antibiotic resistance genes. Environmental Pollution, 254(B). 113067.

25. NOM-114-SSA1. (1994). Procedimientos para la determinación de Salmonella. Bienes y servicios. Norma Oficial Mexicana, Secretaría de Salud Pública. Dirección General de Normas, 1-9 pp.

26. NOM-037-PESC-2004. (2004). Pesca responsable en el sistema lagunar de los humedales del Usumacinta, ubicado en los estados de Chiapas, Tabasco y Campeche. Especificaciones para el aprovechamiento de los recursos pesqueros. Norma Oficial Mexicana. Secretaría de Salud Pública. Dirección General de Normas.

27. Orr J. C., Fabry V. J., Aumont O., Bopp L., Doney S. C., Feely R. A., Gnanadesikan A., Gruber N., Ishida A., Joos F., Key R. M., Lindsay K., Maier-Reimer E., Matear R., Monfray P., Mouchet A., Najjar R. G., Plattner G. K., Rodgers K. B., Sabine C. L., Sarmiento J. L., Schlitzer R., Slater R. D., Totterdell I. J., Weirig M. F., Yamanaka Y., \& Yool A. (2005). Anthropogenic ocean acidification over the twentyfirst century and its impact on calcifying organisms. Nature, 437: 681686.

28. Proia L., Anzil A., Subirats J., Borrego C., Farré M., Llorca M., Balcázar J. L., \& Servais P. (2018). Antibiotic resistance along an 
urban river impacted by treated wastewaters. Science of the Total Environmental, 628-629: 453-466.

29. Ugollini, F. I. (2006). Estudio bacteriológico de aguas recreacionales de balnearios del río Limay en la ciudad de Neuquén, Argentina.

30. Watkinson, A., Micalizzi, G., Graham, G., Bates, J., \& Costanzo, S. (2007). Antibiotic-resistant Escherichia coli in wastewaters, surface waters, and 36 oysters from an urban riverine system. Applied and Environmental Microbiology, 73(17): 5667-5670.

31. Zhu Y. G., Zhao Y., Li B., Huang C. L., Zhang S. Y., Yu S., Chen Y. S., Zhang T., Gillings M. R., \& Su J. Q. (2017). Continental-scale pollution of estuaries with antibiotic resistance genes. Nature Microbiology, 2(16270). 